\title{
Establecimiento in vitro de granadilla silvestre (Passiflora foetida L.) a partir de yemas axilares
}

\author{
In vitro establishment of wild passion fruit (Passiflora foetida L.) from axillary buds
}

Angel David Hernández Amasifuen ${ }^{1}$, Alexis Argüelles Curaca ${ }^{1}$, Anthony Apolinario Cortez Lazaro ${ }^{1}$ Hermila Belba Díaz Pillasca ${ }^{1}$

\begin{abstract}
RESUMEN
Objetivo: Establcer in vitro a la granadilla silvestre (Passiflora foetida L.) a partir de yemas axilares. Material y Métodos: El material vegetal fue seleccionado de invernadero y se le realizo un proceso de desinfección a difentes porcentajes de hipoclorito de sodio $(0,0.5,1,1.5$ y $2 \%)$, luego cada explantes fue colocado en envases de plastico conteniendo medio Murashige y Skoog (MS) a diferentes concentraciones de las sales bases (100, 75, 50 y 25\%). Resultados: Los resultados obtenidos mostraron que al emplear Hipoclorito de Sodio a partir del $1 \%$ se presenta menor porcentaje de contaminación. Mientras tanto en la concentración de sales MS no se encontró diferencia significativa en la formación de brotes y longitud entre los tratamientos al 100, 75 y $50 \%$. Conclusión: Se logró el establecimiento in vitro a la granadilla silvestre (Passiflora foetida L.) a partir de yemas axilares.
\end{abstract}

Palabras clave: Passiflora foetida L., granadilla silvestre, in vitro, yemas axilares.

\section{ABSTRACT}

Objective: Establish in vitro the wild granadilla (Passiflora foetida L.) from axillary buds. Material and Methods: The plant material was selected from the greenhouse and a disinfection process was carried out at different percentages of sodium hypochlorite $(0$, $0.5,1,1.5$ and $2 \%$ ), then each explant was placed in plastic containers containing Murashige and Skoog medium (MS) at different concentrations of the base salts $(100,75,50$ and $25 \%)$. Results: The results obtained showed that when using Sodium Hypochlorite from $1 \%$, there is a lower percentage of contamination. Meanwhile, in the concentration of MS salts there was no significant difference in the formation of shoots and length between treatments at 100,75 and $50 \%$. Conclusion: In vitro establishment of wild granadilla (Passiflora foetida L.) was obtained from axillary buds.

Keywords: Passiflora foetida L., wild granadilla, in vitro, axillary buds.

\section{INTRODUCCIÓN}

El género Passiflora es el más importante dentro de la familia Passifloraceae, por presentar gran valor económico y tambien por ser usada en la medicina tradicional. Su mayor caracteristica son sus frutos comestibles, siendo los mas conocidos a nivel mundial el maracuya, la granadilla (Avilán et al., 1992).

También en la costa peruana se ha descrito a la granadilla silvestre o granadilla de culebra (Passiflora foetida L.). Es una hierba trepadora con zarcillos, y las flores son de color blanco a crema pálido y de 5 a $6 \mathrm{~cm}$ de diámetro con brácteas pinnatífidas de 2 a 4 veces en la base. La planta generalmente está dispersa, crece en matorrales y lechos de ríos y suelos de bosques secos. Además se presentan productos naturales derivados de plantas como los flavonoides, terpenos y alcaloides han recibido una atención considerable en los últimos años debido a su método respetuoso con el medio ambiente para curar dolencias (Park, 2018).

Debido a las importantes propiedades medicinales de esta planta, se podrían aplicar herramientas biotecnológicas como vienen siendo las técnicas de cultivo de células y tejidos vegetales para la rápida y masiva propagación de plantas valiosas medicinales y económicas (Shekhawat et al. 2015); así mismo provee ADN para estudios moleculares, plántulas para estudios ecológicos y material para usos económicos. Entre estas técnicas se encuentran la micropropagación, embriogénesis somática, organogénesis y criopreservación (Sarasan et al., 2006).

En el empleo de tejidos vegetales in vitro se aprovecha al máximo la totipotencia de las células vegetales para formar nuevos tejidos e inclusos individuos a partir de una sola celula en acelerada multiplicación, como pueden otras células recuperar su condición meristemática.

Por lo tanto se necesita de un explante inicial a partir de una planta madre adecuada, el cual será previsto de los nutrientes, fuentes de carbono, vitaminas y hormonas vegetales necesarias para la formación de brotes y/o raíces (Barnicoat et al., 2011) Se debe tener en consideración que el explante inicial puede ser cualquier parte de una planta, desde yema hasta una antera o microspora (Hernández y Díaz, 2019), pero la respuesta morfogenética deseada dependerá de la especie, explante y composición del medio de cultivo, considerando que todo además estará regulado por el balance hormonal propio y por el estado fisiológico del órgano, tejido o célula puesta en cultivo (Segretín, 2006).

Por lo tanto en la busqueda de medios de conservación y multiplicación de especie silvestres con importancia y valoración a futuro se considera la aplicación de técnicas de cultivo de tejidos vegetales in vitro, de esta manera el presente trabajo de investigaicón presenta como objetivo establcer in vitro a la granadilla silvestre (Passiflora foetida L.) a partir de yemas axilares.

\section{MATERIAL Y MÉTODOS}

La presente investigación se llevó a cabo en las instalaciones del laboratorio de Biotecnología Vegetal de la Escuela Profesional de Biología con mención en Biotecnología, ubicado en la Universidad Nacional José Faustino Sánchez Carrión, Huacho, Lima, Perú. Asi mismo el material vegetal de la especie Passiflora foetida $\mathrm{L}$. fue seleccionado del invernadero perteneciente al laboratorio de Biotecnología vegetal.

Las muestras vegetales fueron colectadas y seleccionadas de 3 a 4 nudos con un largo de 10 a $20 \mathrm{~cm}$. Una vez cortados, los explantes se lavaron con agua destilada con una gota de "Ayudin Actibacterial" durante 
5 minutos y a la vez fueron cepilladas suavemente. Posteriormente se sumergieron en una solución de alcohol al $70 \%$ por 60 segundos, luego se trasladó a la cámara de flujo laminar para continuar con la desinfección de los explantes, luego se sumergió en distintas soluciones de hipoclorito de sodio $(\mathrm{NaClO})$ para determinar el porcentaje con mayor poder de desinfección y menor daño en el tejido vegetal, las concentraciones de las soluciones de hipoclorito de sodio fueron al $0 ; 0,5 ; 1 ; 1,5$ y $2 \%$, y se pusieron en contacto durante 10 minutos y se continuó con tres enjuagues en agua destilada estéril. Posteriormente los explantes se enjuagaron y colocaron sobre papel filtro estéril para realizar los cortes los extremos, y luego se introdujo un explante en un envase de plástico con medio de cultivo MS.

El medio de cultivo MS, consistió en sales descritas por Murashige y Skoog (1962), las cuales fueron divididas en tratamientos para determinar las concentraciones óptimas para el establecimiento in vitro de la grandilla silvestre (Tabla 1). Luego se ajustado a un $\mathrm{pH}$ de 5,8, y los medios fueron llevados al autoclave para su esterilización a presión de 1,2 Bar con temperatura de $121^{\circ} \mathrm{C}$ durante 20 minutos.

Tabla 1.

Tratamientos del medio de cultivo in vitro para explantes de Passiflora foetida L.

\begin{tabular}{cccccc}
\hline Tratamiento & $\begin{array}{c}\text { Concentración } \\
\text { de MS }(\%)\end{array}$ & Sacarosa $(\mathrm{g} / \mathrm{L})$ & $\begin{array}{c}\text { Agar agar } \\
(\mathrm{g} / \mathrm{L})\end{array}$ & $\begin{array}{c}\text { Tiamina } \\
\mathrm{HCl}(\mathrm{mg} / \mathrm{L})\end{array}$ & $\begin{array}{c}\text { Mioinositol } \\
(\mathrm{mg} / \mathrm{L})\end{array}$ \\
\hline T1 & 100 & 25 & 7 & 0,1 & 100 \\
T2 & 75 & 25 & 7 & 0,1 & 100 \\
T3 & 50 & 25 & 7 & 0,1 & 100 \\
T4 & 25 & 25 & 7 & 0,1 & 100 \\
\hline
\end{tabular}

Los explantes se mantuvieron en cámara de crecimiento a una temperatura de $25^{\circ} \mathrm{C}, 75 \%$ de humedad y 1500 Lux, con un fotoperiodo de 16 horas de luz y 8 de oscuridad.

El diseño experimental fue al azar con 15 envases de plástico por tratamiento conteniendo cada uno de ellos un explante de granadilla silvestre. Durante el experimento se realizó la evaluación de contaminación (\%), necrosis u oxidación (\%) y explantes que sobrevivieron (\%). En la determinación del porcentaje del MS se evaluó longitud, número de hojas y enraizamiento. Se empleó el paquete estadístico agricolae del software libre $R$ versión 3.6.1, donde se procesaron los datos mediante Análisis de Varianza
(ANOVA) y Tukey $(p \leq 0.05)$ para la comparación de medias.

\section{RESULTADOS}

La Tabla 2 muestra los resultados obtenidos de la evaluación del efecto del hipoclorito de sodio en la desinfección los explantes de granadilla silvestres, la cual se realizó a los diez días posterior a la introducción in vitro. Los mejores resultados de desinfección se obtuvieron a partir del empleo del hipoclorito de sodio al $1 \%$, pero a medida que incrementan las concentraciones se produce oxidación de los explantes.

Tabla 2

Efecto del hipoclorito de sodio en la desinfección de los explantes de Passiflora foetida L.

\begin{tabular}{ccccc}
\hline Tratamiento & $\begin{array}{c}\text { NaClO } \\
(\%)\end{array}$ & $\begin{array}{c}\text { Contaminación } \\
(\%)\end{array}$ & $\begin{array}{c}\text { Oxidación } \\
(\%)\end{array}$ & $\begin{array}{c}\text { Sobrevivencia } \\
(\%)\end{array}$ \\
\hline 1 & 0 & $92 \mathrm{a}$ & $0 \mathrm{c}$ & $8 \mathrm{e}$ \\
2 & 0,5 & $39 \mathrm{~b}$ & $0 \mathrm{c}$ & $61 \mathrm{c}$ \\
3 & 1 & $7 \mathrm{c}$ & $0 \mathrm{c}$ & $93 \mathrm{a}$ \\
4 & 1.5 & $0 \mathrm{~d}$ & $12 \mathrm{~b}$ & $88 \mathrm{~b}$ \\
5 & 2 & $0 \mathrm{~d}$ & $54 \mathrm{a}$ & $46 \mathrm{~d}$ \\
\hline
\end{tabular}

Medias con la misma letra en cada columna son estadísticamente iguales (Tukey $p \leq 0,05$ ). 
De los resultados obtenidos en la determinación de la concentración del medio MS para granadilla silvestre (Tabla 3), no se presentó diferencia significativa entre los tratamientos T1, T2 y T3. Por lo que se puede emplear el medio MS desde una concentración al 50\% para considerar como posible ahorro de costos.

Se realizó además observaciones semanales para apreciar los posibles cambios morfológicos que tendrían los explantes, de esta manera transcurrida la primera semana del cultivo se observó el crecimiento de los primeros brotes, al pasar los 14 días se dio el incremento del tamaño de las hojas (Figura 1A), mientras que a los 21 días mayor longitud en los explantes (Figura 1B). A partir de la tercera semana se presentaron mayor número de hojas (Figura 2A) mientras que a la cuarta semana presentaron un promedio de 6 hojas por explante (Figura 2B).

Tabla 3

Efecto de concentración de MS en explantes de Passiflora foetida L.

\begin{tabular}{cccc}
\hline Tratamiento & $\begin{array}{c}\text { Promedio de } \\
\text { longitud de brotes } \\
(\mathrm{mm})\end{array}$ & $\begin{array}{c}\text { Promedio de } \mathrm{N}^{\circ} \\
\text { de hojas por } \\
\text { explante }\end{array}$ & $\begin{array}{c}\text { Promedio de } \\
\text { explantes } \\
\text { enraizados }\end{array}$ \\
\hline T1 & $42,4 \mathrm{a}$ & $5,3 \mathrm{a}$ & $11,2 \mathrm{a}$ \\
T2 & $41,7 \mathrm{a}$ & $5,2 \mathrm{a}$ & $9,8 \mathrm{~b}$ \\
T3 & $41,4 \mathrm{a}$ & $4,1 \mathrm{~b}$ & $9,5 \mathrm{~b}$ \\
$\mathrm{~T} 4$ & $19,7 \mathrm{~b}$ & $2,6 \mathrm{c}$ & $4,7 \mathrm{c}$ \\
\hline
\end{tabular}

Medias con la misma letra en cada columna son estadísticamente iguales (Tukey $p \leq 0,05$ ).
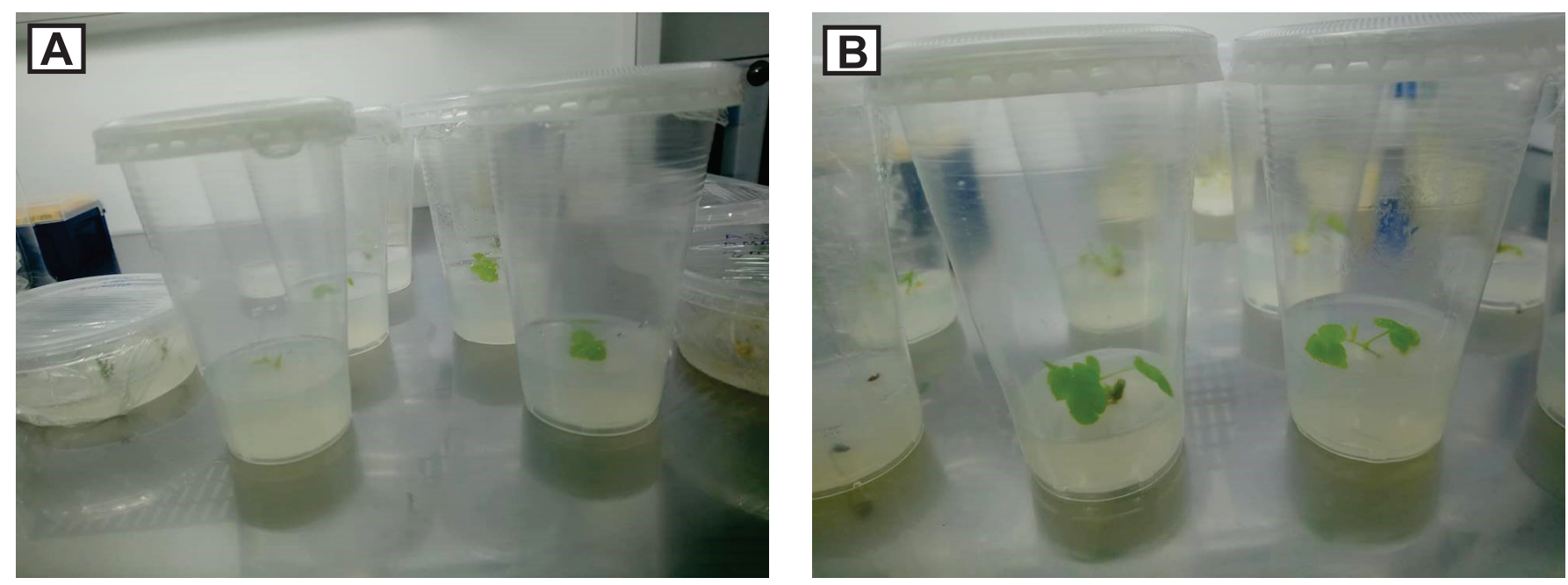

Figura 1 Brotes de Passiflora foetida L. a los 14 días (A) y a los 21 días (B) del establecimiento in vitro.
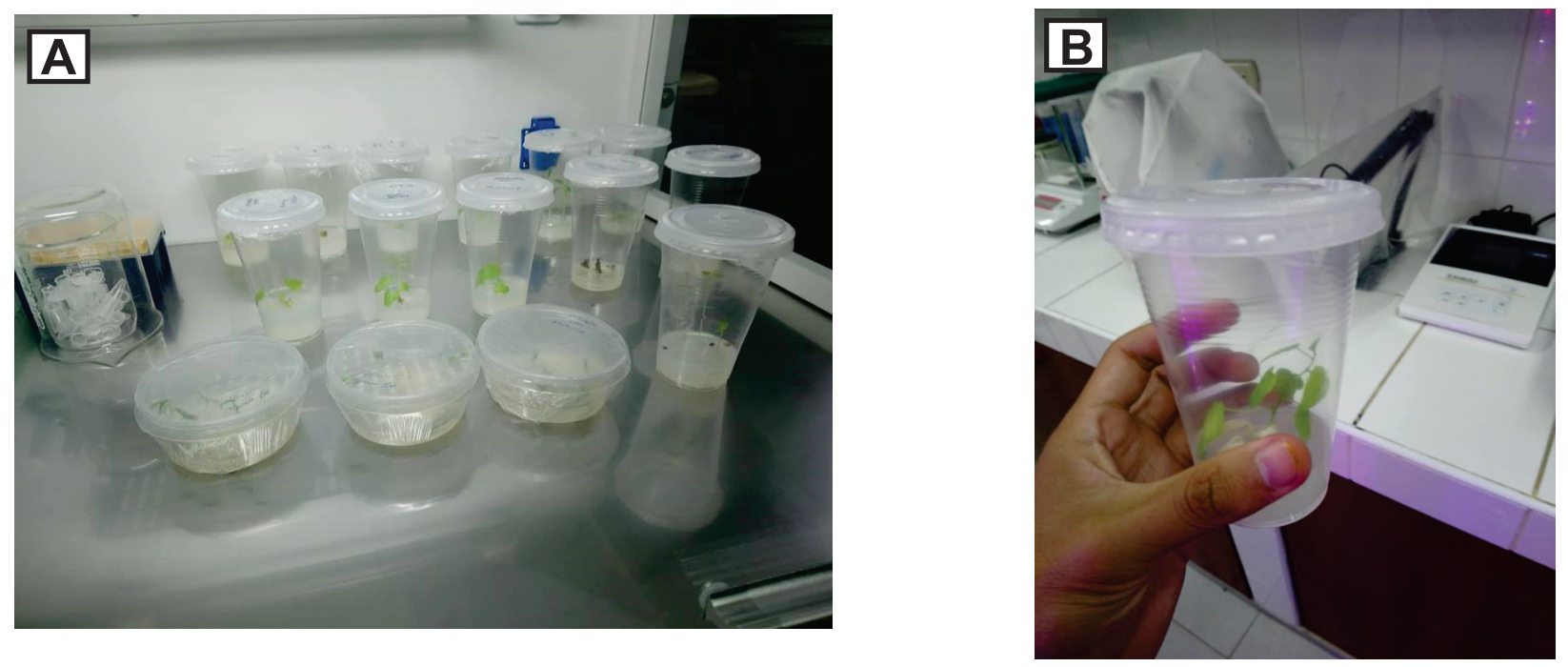

Figura 2 Medios con Passiflora foetida L. a los 28 días (A) y a los 35 días (B). 


\section{DISCUSIÓN}

El método de desinfección para Passiflora foetida L. con hipoclorito de sodio al $1 \%$ permitió obtener mayor porcentaje de sobrevivencia (93\%), presentando mayor sobrevivencia en comparación a los resultados obtenidos por otros autores en distintas especies de Passiflora, como Otahola y Díaz (2010), quienes obtuvieron $78,67 \%$ y $66,67 \%$ de sobrevivencia a partir de yemas laterales de $P$. edulis y $P$. quandragularis respectivamente, experimento en el cual emplearon hiplocorito de sodio al $1,25 \%$ durante 20 minutos. Mientras que Hernández et al. (2018), obtuvieron 86\% de sobrevivencia a partir de yemas axilares de $P$. edulis al emplear $\mathrm{NaClO}$ al 1,5\% durante 10 minutos.

En la determinación del porcentaje de sales MS en el medio de cultivo, no se presentaron diferencias significativas al emplear $100 \%, 75 \%$ y $50 \%$ en la altura de los brotes regenerados, pero en el número de hojas los tratamientos que presentaron diferencias significativas fueron el T1 y T2, mientras que en promedio de enraizamiento el que presente mayor explantes enraizados fue el T1. Por lo que en la regeneración de brotes a partir de yemas axilares se logró obtener que el medio de cultivo MS fue suficiente para la regeneración y elongación del explante de $P$. foetida. Resultados similares se compararon in vitro de $P$. edulis, $P$. quandragularis (Otahola \& Díaz, 2010; Hernández et al., 2018) y P. mollissima (Palacios, 2015); mientras que Flores et al. (2015), en su etapa de establecimiento in vitro y micropropagación de $P$. ligularis necesito adicionar al medio MS la citoquinina 6-bencilaminopurina (BAP) en una concentración de $3,5 \mathrm{mg} / \mathrm{L}$ para lograr que sus explantes presentaran brotes.

Cabe señalar que no fue necesario emplear auxinas en el medio de cultivo para lograr el enraizamiento, ya que en el mismo medio MS los explantes llegaron a formar raíces. Por lo que se puede tener en cuenta que esta especie vegetal no necesita de hormonas exógenas para iniciar con la organogénesis, en relación a la intervención tanto de la formación de brotes, hojas y raíces por hormonas endógenas las cuales son frecuentes en plantas herbáceas silvestres que promueven la organogénesis in vitro (Randall et al., 2014).

\section{CONCLUSIONES}

Se estableció in vitro a la granadilla silvestre (Passiflora foetida L.) a partir de yemas axilares, obteniendo de un porcentaje de sobrevivencia del 93\% empleando hipoclorito de sodio al $1 \%$ durante 10 minutos, y no se logró encontrar diferencias significativas al emplear las sales MS en concentraciones entre 100 al $50 \%$.

\section{REFERENCIAS BIBLIOGRAFICAS}

Avilan, L., Leal, F. y Baustista, D. (1992). Manual de Fruticultura. Tomo II Editorial AMÉRICA, C.A. $2^{\circ}$ Edición. Caracas, Venezuela. $531 \mathrm{p}$.

Barnicoat H., Cripps, R. y Kendon, J. (2011). Conservation in vitro of rare and threatened ferns-case studies of biodiversity hotspot and island species. In Vitro Cellular \& Developmental Biology - Plant 47(1): 37-45. https://doi.org/10.1007/ s11627-010-9303-X.

Flores, D., Brenes, J. y Guzmán, A. (2015). Propagación por estacas y estudio preliminar del establecimiento in vitro de granadilla (Passiflora ligularis, juss).
Tecnología en Marcha18 (2) Especial. 86 - 90.

Hernández, A. y Díaz, H. (2019). Inducción in vitro de callo embriogénico a partir del cultivo de anteras en "papa amarilla" Solanum goniocalyx Juz. \& Bukasov (Solanaceae). Arnaldoa 26 (1): 277 - 286. http://doi.org/10.22497/arnaldoa.261.26111

Hernández, A., Durand, M., Gózalo, A., Domínguez, G. y Díaz, H. (2018). Micropropagación de Passiflora edulis a partir de yemas axilares. Libro 6ta Feria Universitaria de Ciencia, Tecnología y Humanismo 2018: 63 - 69 p.

Murashige, T. y Skoog, F. (1962). "A Revised Medium for Rapid Growth and Bio Assays with Tobacco Tissue Cultures". Physiologia Plantarum. 15 (3): 473-497.

Otahola, V. y Díaz, M. (2010). Regeneración in vitro de Passiflora edulis f. flavicarpa y Passiflora quadrangularis utilizando dos tipos de explantes provenientes de plantas adultas y bencilaminopurina. Revista Científica UDO Agrícola $10(1):$ 23-28.

Palacios, J. (2015). Establecimiento in vitro de tumbo serrano (Passiflora mollissima (Kunth) L.H. Bailey) en el laboratorio de biotecnología vegetal de la facultad de ciencias agropecuarias. (Tesis de pregrado, Universidad Nacional Jorge Basadre Brohmann, Tacna, Perú). Recuperado de: http://repositorio.unjbg.edu.pe/bitstream/handle/UN JBG/1843/930 2016 palacios calisaya jlfcag_agronomia.p̄df?sequence=1\&isAllowed=y

Park, J. W. (2018). Efectos antiinflamatorios de Passiflora foetida $L$. en macrófagos RAW264.7 estimulados con LPS. Revista Internacional de Medicina Molecular 41 (6): 3709-3716.

Randall, C., Flores, D., Alvarado, L., Schmidt A. y Alvarado, C. (2014). Cultivo in vitro del tomate de árbol (Cyphomandra betacea (Cav.) Sendt. (Fenotipo naranja) proveniente de Costa Rica. Tecnología en Marcha. Revista VI Encuentro de Investigación. 45-55.

Sarasan, V., Cripps, R., Ramsay, M. M., Atherton, M. M., Prendergast, G. y Rowtherton, J.K (2006). Conservation in vitro of thre atened plants; progress in the past decade. In Vitro Cellular y development Biology Plants 42:206-214.

Segretín, M. (2006). Los cultivos celulares y sus aplicaciones II (cultivos de células vegetales). ArgenBio 1 (6).

Shekhawat M. S., Kannan, N. \& Manokari, M. (2015). In vitro regeneration of shoots and ex vitro rooting of an important medicinal plant Passiflora foetida $L$. through nodal segment cultures. Journal of Genetic Engineering and Biotechnology, 13(2), 209-214. Doi: http://doi.org/10.1016/j. jgeb.2015.08.002. 